\title{
White Organic Light Emitting Devices Based on Multiple Emissive Nanolayers
}

\section{V. Madhava Rao*, Yan Kuin Su, T. S. Huang and Yi-Chun Chen}

In this paper, a white organic light-emitting device (WOLEDs) with multiple-emissive-layer structure has been fabricated. The device has a simple structure of indium tin oxide (ITO)/NPB $(20 \mathrm{~nm}) / /$ DPVBi$(20 \mathrm{~nm}) /$ CDBP:xIr(btp)2acac(10 nm)/Alq3 (25 nm)/BCP (5 nm)/CsF (1 nm)/Al (150 $\mathrm{nm})(\mathrm{x}=0.15,2.5$ and $3.0 \mathrm{wt} \%)$, where $\mathrm{NPB}$ and $\mathrm{BCP}$ are used as the hole-injecting layer, electron transporting and hole blocking layer, respectively. White light emission was realized in an OLED with $2.5 \% \operatorname{Ir}(\mathrm{btp}) 2 \mathrm{acac}$ doping concentration. The device exhibits peak efficiency of $1.93 \mathrm{~cd} / \mathrm{A}$ at $9 \mathrm{~V}$ and maximum brightness of $7005 \mathrm{~cd} / \mathrm{m}^{2}$ at $14 \mathrm{~V}$. The Commission International de I'Eclairage (CIE)(1931) coordinates of white emission are well within the white zone, which moves from $(0.35,0.33)$ to $(0.26,0.30)$ when the applied voltage is varied from $5 \mathrm{~V}$ to $14 \mathrm{~V}$.

Keywords: Multilayer structure; Organic light-emitting device; White emission

Citation: M. V. Madhava Rao, Yan Kuin Su, T. S. Huang and Yi-Chun Chen, "White Organic Light Emitting Devices Based on Multiple Emissive Nanolayers”, Nano-Micro Lett. 2, 242-246 (2010). doi:10.3786/nml.v2i4.p242-246

White organic light-emitting devices (WOLEDs) have attracted considerable interest in the last decade for their applications as a large size display, a backlight for liquid crystal display, and a light source for general illumination. They have many advantages over other displays or light sources such as flexibility, design freedom, thin and light, distributed light emission, and low cost manufacturing [1-6].

In order to generate the desired white light, WOLEDs with various configurations have been proposed [7-13], such as: (a) a multilayer device with blue, green, and red emission layers; (b) a doped device with a host material and blue, green, and red fluorescence dyes; (c) a single emission layer device with white emission materials; (d) excimer and exciplex emission; and (e) tandem structure [14-23]. Among these approaches, WOLEDs employing multi-emissive layer structure has advantages over other architectures in terms of efficiency and color controlability because the recombination current, singlet and triplet energy transfer and performance of each layer can be controlled by layer thickness, doping concentration and charge blocking layers. One important drawback of the WOLEDs with multi-emissive layers is the color shift with increasing voltage [24-28]. The color shift is believed to be originated from the shift of recombination zone with increasing voltage and easier formation of high energy excitons at higher voltage [29].

Recently, highly efficient WOLEDs using phosphorescent materials with incorporated heavy metal complexes have been reported [12,27]. Since fluorescent OLEDs which utilize only the singlet excitons, phosphorescent OLEDs have proven to be potentially more efficient because they can harvest both single and triplet excitons and have the potential of reaching a maximum internal efficiency of $100 \%$. Among all phosphorrescent materials, iridium metal complexes are the most famous material due to the relatively short lifetime of their triplet state. In this letter, we demonstrate a efficient white organic light emitting devices fabricated by the phosphorescent organic materials. The white emission (Commission International de I'Eclairage 1931) chromaticity coordinate $(0.35,0.33)$ was obtained using blue-emitting 4,4'-bis(2,2'-diphenylvinyl)-1, 1 '-biphenyl(DPVBi), green-emitting (Alq3), and red emitting (CDBP-Ir(btp)2acac). We could obtain the contribution of red

Institute of Microelectronics, Department of Electrical Engineering, and Advanced Optoelectronic Technology Center, National Cheng Kung University, Tainan 701, Taiwan, ROC.

*Corresponding author. E-mail: madhavmora@yahoo.com 
light by completing energy transfer from CDBP to $\operatorname{Ir}(\mathrm{btp}) 2 \mathrm{acac}$ when the optimum doped concentration of $\operatorname{Ir}(\mathrm{btp}) 2 \mathrm{acac}$ is $2.5 \%$.

\section{Experimental}

The configuration of the devices is ITO/N,N'-bis(1-naphthyl)-N,N'-biphenyl-1,1'-biphenyl-4,4'-diamine(NPB) $(20 \mathrm{~nm}) / \operatorname{DPVBi}(20 \mathrm{~nm}) / \mathrm{CDBP}: x \operatorname{Ir}(\mathrm{btp}) 2 \operatorname{acac}(10 \mathrm{~nm}) / \operatorname{Alq} 3(25$ $\mathrm{nm}) / \mathrm{BCP}(5 \mathrm{~nm}) / \mathrm{CsF}(1 \mathrm{~nm}) / \mathrm{Al}(150 \mathrm{~nm}),), \mathrm{x}=0.15,2.5$ and 3.0 $\mathrm{wt} \%$, and the corresponding devices are named Device $\mathrm{A}$, Device B and Device C. NPB acted as hole transporting layer (HTL), BCP as electron transporting layer, and hole blocking layer (ETL/HBL). All devices were grown onto a pre-cleaned ITO coated glass substrate with resistance of $20 \mathrm{Ohm} / \mathrm{sq}$. The ITO coated substrates were routinely cleaned with detergent, distilled water, acetone, and 2-propanol in ultrasonic bath. The substrates were dried in an oven at $100^{\circ} \mathrm{C}$ before treated with UV-Ozone. After 25 minutes, all organic layers were deposited in succession without breaking vacuum $\left(10^{-6} \mathrm{~Pa}\right)$. Thermal

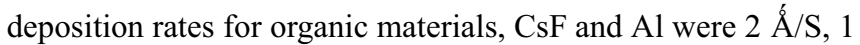

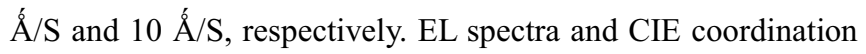
of the devices were measured by PR650 spectra scan spectrometer. The current-voltage-brightness characteristics were simultaneously measured by a Keithley 2400 programmable voltage-current source. All the measurements were carried out at room temperature under ambient condition. Figure 1 shows the molecular structure of organic materials used in this study. The active emissive area of the device is $6 \mathrm{~mm}^{2}$.

\section{Results and Discussion}

Figure 2(a) and (b) show relationship of the current density versus voltage and the luminance versus voltage of devices $\mathrm{A}, \mathrm{B}$ and $\mathrm{C}$, respectively. At $15 \mathrm{~V}$, the devices $\mathrm{B}$ archived the maximum luminance of $7005 \mathrm{~cd} / \mathrm{m}^{2}$. The turn-on voltage (the bias required to give a measurable luminance of $1 \mathrm{~cd} / \mathrm{m}^{2}$ ) of all the devices was about $6 \mathrm{~V}$. The inset of Fig. 2(b) shows the luminance efficiency-voltage characteristics of devices A, B and C. The maximum efficiency was $1.93 \mathrm{~cd} / \mathrm{A}$, while the voltage was $9 \mathrm{~V}$ and luminance was $375 \mathrm{~cd} / \mathrm{m}^{2}$. The luminance efficiencies are increased to the maximum and then decreased at higher voltage.

The typical EL spectra of devices A, B and C are presented in Fig. 3(a). It can be seen that the peaks of typical EL spectra locate at 470 and $620 \mathrm{~nm}$, respectively, corresponding to the CIE coordinates of $(0.35,0.33)$ which are very close to the optimum white region of $(0.33,0.33)$. It also shows that the EL spectra responsible for white light emission of the device. For this device, the CIE coordinates of $(0.35,0.33)$ were independent on bias voltages. From the view of doping, the red light emission is from $\operatorname{Ir}(\mathrm{btp}) 2 \mathrm{acac}$ layer due to incomplete energy transfer.

The emission peak of $\operatorname{Ir}(\mathrm{btp}) 2 \mathrm{acac}$ is at around $610 \mathrm{~nm}$ and a shoulder at $670 \mathrm{~nm}$. We can find that the intensity of the red peak increases with increasing the concentration of $\operatorname{Ir}(\mathrm{btp}) 2 \mathrm{acac}$ from 1.5 to $3.5 \%$. Hence, the intensities of emission peaks at 610 and $670 \mathrm{~nm}$ increase as the concentration of $\operatorname{Ir}(\mathrm{btp}) 2 \mathrm{acac}$ increased.
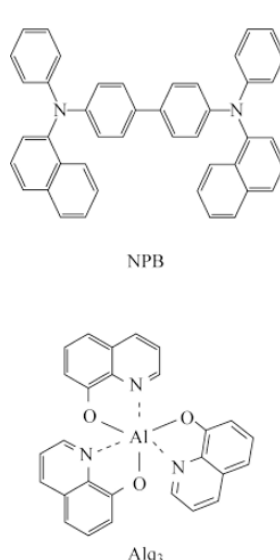

$\mathrm{Alq}_{3}$
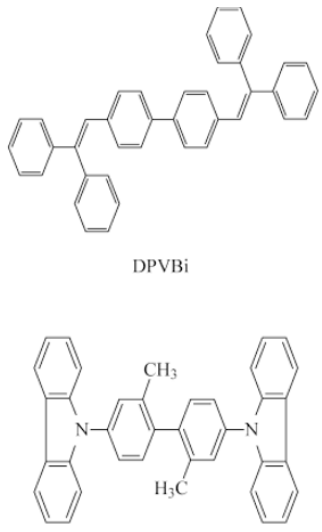

CDBP

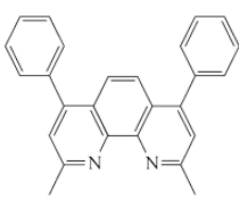

$\mathrm{BCP}$

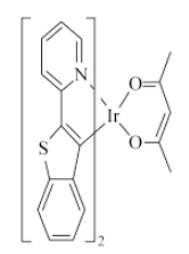

$\operatorname{Ir}($ btp)2acac

FIG. 1. Chemical structure of the NPB, DPVBi, BCP, Alq3, CDBP and Ir(btp)2acac materials 

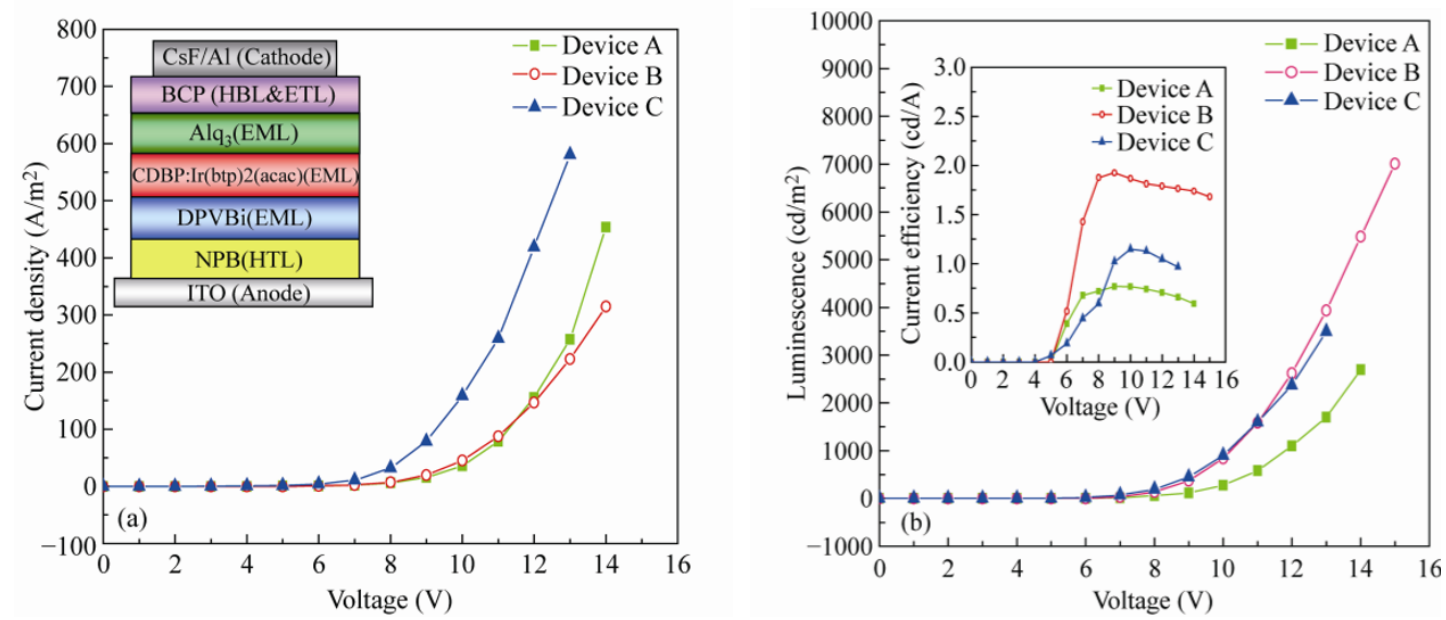

FIG. 2. (a) Current density versus voltage (I-V). The Inset shows device schematic diagram in this study. (b) Luminance versus Voltage (L-V) characteristics of device.

The inset shows EL efficiency versus voltages characteristics.
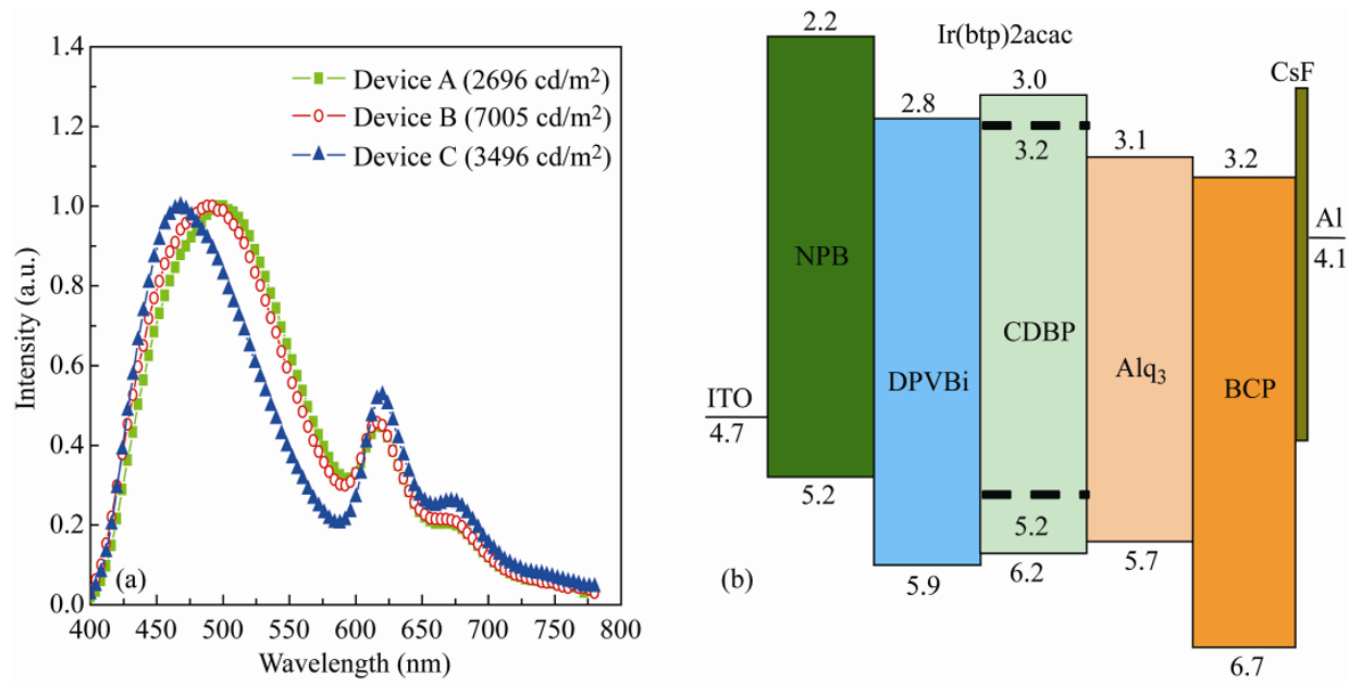

FIG. 3. (a) Normalized EL spectrum of the device of A, B, and C. (b) The energy-level diagram of the white organic light emitting devices.
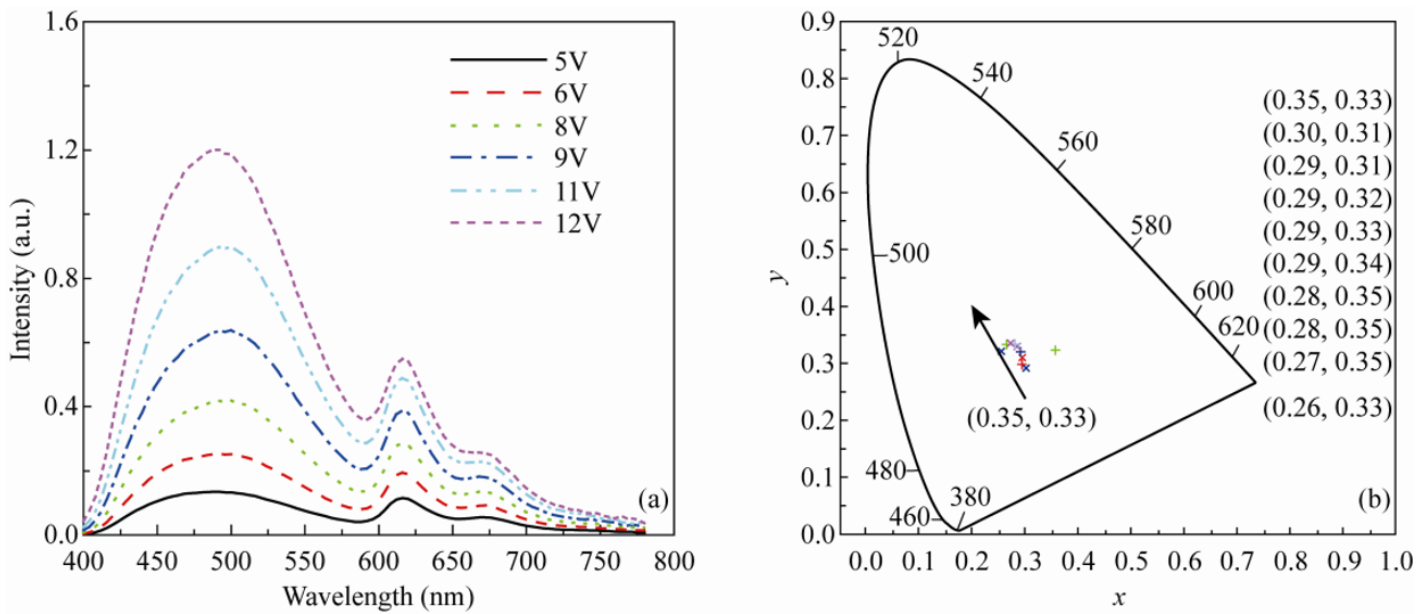

FIG. 4. (a) Normalized EL intensity of the device B at different voltages. (b) The CIE coordinates of white light emitting device at various biases.

Figure 3(b) shows the proposed energy level diagram of the devices. According to the energy diagram, the Red emission has two possible excitation ways: not due to the energy transfer from CDBP, but from the direct recombination of injected carriers at the red dopant sites. As the concentration of $\operatorname{Ir}(\mathrm{btp}) 2 \mathrm{acac}$ is low, the number of carriers trapping on $\operatorname{Ir}(\mathrm{btp}) 2 \mathrm{acac}$ molecules is less. Thus, more excitons may form at $\mathrm{CDBP} / \mathrm{Alq} 3$ interface and recombine in the CDBP layers, resulting in an increased 
emission from CDBP. The intensity of the red emission increases relative to the blue emission. This is attributed to more trapped carriers on $\operatorname{Ir}(b t p) 2 a c a c$ molecules or the increased energy transfer from CDBP to $\operatorname{Ir}(\mathrm{btp}) 2 \mathrm{acac}$. The CIE coordinates of the devices with $2.5 \% \operatorname{Ir}(\mathrm{btp}) 2 \mathrm{acac}$ are $(0.35,0.33)$, which is fairly close to the white-light equi-energy point $(0.33,0.33)$.

Figure 4(a) shows the normalized EL spectra of the white emission device with $2.5 \mathrm{wt} \% \mathrm{Ir}$ in CDBP at different voltages. The broad peak of blue-greenish emission includes the emission spectra of DPVBi and Alq3. The primary peaks at $460 \mathrm{~nm}$, and $610 \mathrm{~nm}$ are attributed to the fluorescent emission of DPVBi and Ir(btp)2acac. As it can be seen, the emission intensity of $\operatorname{Ir}(\mathrm{btp}) 2 \mathrm{acac}$ decreases with change in the different voltages of device. Because part of injected electrons and holes on the Ir(btp)2acac molecules recombine and the doped concentration of $\operatorname{Ir}(\mathrm{btp}) 2 \mathrm{acac}$ is only $2.5 \%$, the contribution of $\operatorname{Ir}(\mathrm{btp}) 2 \mathrm{acac}$ emission is limited. As the bias voltage increases, the more carriers recombine in DPVBi and Alq3. Hence, the emission intensity of red light decreases and the emission intensity of blue-greenish light increased by increasing the current. Thus, the saturated white emission with the CIE coordinates $(0.35,0.33)$ was achieved at $5 \mathrm{~V}$. Figure 4(b) shows the CIE coordinates from $5 \mathrm{~V}$ to $14 \mathrm{~V}$. We can see that the CIE coordinates are not stable over a range of operation voltages and region is just around the equienergy white point.

Table 1 WOLED parameters of devices A, B and C

\begin{tabular}{ccccc}
\hline & $\begin{array}{c}\text { Turn-on } \\
\text { voltage }\end{array}$ & $\mathrm{CIE}(\mathrm{X}, \mathrm{Y})$ & $\begin{array}{c}\text { Luminescence } \\
\left(\mathrm{cd} / \mathrm{m}^{2}\right)\end{array}$ & $\begin{array}{c}\text { Current } \\
\text { efficiency } \\
(\mathrm{cd} / \mathrm{A})\end{array}$ \\
\hline Device A & $8 \mathrm{~V}$ & $(0.33,0.36)$ & 2696 & 0.77 \\
Device B & $8 \mathrm{~V}$ & $(0.35,0.33)$ & 7005 & 1.93 \\
Device C & $8 \mathrm{~V}$ & $(0.33,0.28)$ & 3496 & 1.15 \\
\hline
\end{tabular}

Table 1 displays the efficiency, maximum luminance and CIE coordinate values of all devices. It is obvious that higher concentration of $\operatorname{Ir}(\mathrm{btp}$ )2acac (deice B) results in higher efficiency and the proper concentration produces pure white light emission. We find that the pure white emission with CIE coordinates of $(0.35,0.33)$ at $5 \mathrm{~V}$ produced when the concentration of $\operatorname{Ir}(\mathrm{btp}) 2 \mathrm{acac}$ is $2.5 \mathrm{wt} \%$. In device $\mathrm{B}$, the maximum luminance efficiency of $1.97 \mathrm{~cd} / \mathrm{A}$ and brightness of $7005 \mathrm{~cd} / \mathrm{m}^{2}$ were obtained.

\section{Conclusions}

In summary, we have fabricated electro-phosphorescent white organic light-emitting device with structure of ITO/ $\operatorname{NPB}(20 \mathrm{~nm}) / \operatorname{DPVBi}(20 \mathrm{~nm}) / \mathrm{CDBP}: 2.5 \% \operatorname{Ir}(\mathrm{btp}) 2 \mathrm{acac}(10 \mathrm{~nm})$
/Alq3(25 nm)/BCP(5 nm)/CsF(1 nm)/Al (150 nm). A maximum luminance of $7005 \mathrm{~cd} / \mathrm{m}^{2}$ and efficiency $1.93 \mathrm{~cd} / \mathrm{A}$ are achieved at $14 \mathrm{~V}$ and $9 \mathrm{~V}$, respectively. The CIE coordinates of the devices vary from $(0.35,0.33)$ at $5 \mathrm{~V}$ to $(0.26,0.33)$ at $14 \mathrm{~V}$ and are well within the white region.

The authors would like to thanks the Office of R\&D, National Cheng Kung University, Taiwan.

\section{Received 5 October 2010; accepted 18 November; published online 25 November.}

\section{References}

1. C. W. Tang and S. A. Vanslyke, Appl. Phys. Lett. 51, 913 (1987). doi:10.1063/1.98799

2. C. Adachi, T. Tsutsui and S. Saito, Appl. Phys. Lett. 55, 1489 (1989). doi:10.1063/1.101586

3. X. Mo, T. Mizokuro, C. Heck, N. Tanigaki and T. Hiraga, Nano-Micro Lett. 1, 19 (2009).

4. M. V. Madhava Rao, T. S. Huang, Y. Su, M. Tu, C. Huang and S. Wu, Nano-Micro Lett. 2, 49 (2010).

5. M. V. Madhava Rao, Y. Su, T. S. Huang, M. Tu, S. Wu and C. Huang, J. Electrochem. Soc. 157, H 832 (2010).

6. M. A. Baldo, D. F. O’Brien, Y. You, A. Shoustikov, S. Sibley, M. E. Thompson and S. R. Forrest, Nature 395, 151 (1998). doi:10.1038/25954

7. B. W. D'Andrade and S. R. Forrest, Adv. Mater. 16, 1585 (2004). doi:10.1002/adma.200400684

8. R. S. Deshpande, V. Bulovic and S. R. Forrest, Appl. Phys. Lett. 75, 888 (1999). doi:10.1063/1.124250

9. C. W. Tang, S. A. VanSlyke and C. H. Chen, J. Appl. Phys. 65, 3610 (1989). doi:10.1063/1.343409

10. J. Shi and C. W. Tang, Appl. Phys. Lett. 70, 1665 (1997). doi:10.1063/1.118664

11. C. H. Chuen and Y. T. Tao, Appl. Phys. Lett. 81, 4499 (2002). doi:10.1063/1.1528736

12. S. Tokito and T. Iijima, Appl. Phys. Lett. 83, 2459 (2003). doi:10.1063/1.1611620

13. R. H. Friend, R. W. Gymer, A. B. Holmes, J. H. Burroughes, R. N. Marks, C. Taliani, D. D. C. Bradley, D. A. Dos Santos, J. L. Brédas, M. Lögdlund and W. R. Salaneck, Nature 397, 121 (1999). doi:10.1038/16393

14. J. Kido and Y. Lizumi, Appl. Phys. Lett. 73, 2721 (1998). doi: $10.1063 / 1.122570$

15. F. Steuber, J. Staudigel, M. Stössel, J. Simmerer, A. Winnacker, H. Spreitzer, F. Weissörtel and J. Salbeck, Adv. 
Mater. 12, 130 (2000). doi:10.1002/(SICI)1521-4095 (200001)12:2<130::AIDADMA130>3.0.CO;2-P

16. M. Mazzeo, D. Pisignano, F. Della Sala, J. Thompson, R. I. R. Blyth, G. Gigli, R. Cingolani, G. Sotgiu and G. Barbarella, Appl. Phys. Lett. 82, 334 (2003). doi:10.1063/ $\underline{1.1531217}$

17. F. Li, G. Cheng, Y. Zhao, J. Feng and S. Liu, Appl. Phys. Lett. 83, 4716 (2003). doi:10.1063/1.1632545

18. G. W. Kang, Y. J. Ahn, J. T. Lim and C. H. Lee, Synth. Met. 137, 1029 (2003). doi:10.1016/S0379-6779(02) 00889-5

19. C. H. Kim and J. Shinar, Appl. Phys. Lett. 80, 2201 (2002). doi:10.1063/1.1464223

20. T. Tsuji, S. Naka, H. Okada and H. Onnagawa, Appl. Phys. Lett. 81, 3329 (2002). doi:10.1063/1.1516629

21. S. A. VanSlyke, C. H. Chen and C. W. Tang, Appl. Phys. Lett. 69, 2160 (1996). doi:10.1063/1.117151
22. B. W. D'Andrage, J. Brooks, V. Adamovich, M. E. Thompson and S. R. Forrest, Adv. Mater. 14, 1031 (2002).

23. Y. S. Huang and J. H. Jou, Appl. Phys. Lett. 80, 2782 (2002). doi:10.1063/1.1413220

24. Y. Z. Wang, R. G. Sun, F. Meghdadi, G. Leising and A. J. Epstei, Appl. Phys. Lett. 74, 3313 (1999).

25. C. H. Kim and J. Shinar, Appl. Phys. Lett. 80, 2201 (2002). doi:10.1063/1.1464223

26. K. O. Cheon and J. Shinar, Appl. Phys. Lett. 81, 1738 (2002). doi:10.1063/1.1498500

27. G. Lei, L. Wang and Y. Qiu, Appl. Phys. Lett. 88, 103508 (2006). doi:10.1063/1.2185255

28. X. M. Yu, H. S. Kwok, W. Y. Wong and G. J. Zhou, Chem. Mater.18, 5097 (2006). doi:10.1021/cm061030p

29. Y. Shao and Y. Yang, Appl. Phys. Lett. 86, 073510 (2005). doi:10.1063/1.1866216 